\title{
THIRTY-DAY OPERATIVE MORTALITY FOR THORACOTOMY IN LUNG CANCER
}

Hiromi Wada, $\mathrm{MD}^{\mathrm{a}}$

Takayuki Nakamura, MD $^{\mathrm{b}}$

Kenbu Nakamoto, MD $^{\mathrm{b}}$

Masazumi Maeda, MD $^{\mathrm{c}}$

Yoh Watanabe, $\mathrm{MD}^{\mathrm{d}}$
Objective: The 30-day operative mortality for thoracotomy in lung cancer is described herein. Methods: From January 1994 through December 1994, the Japanese Association for Chest Surgery surveyed the number of thoracotomies for lung cancer by operative procedure, age, and operative mortality. The operative mortality was defined as death within $\mathbf{3 0}$ days of operation. Results: The total number of operations was 7099. The overall 30-day operative mortality was $\mathbf{1 . 3 \%}$. By operative procedure, the mortalities were $\mathbf{3 . 2} \%$ for pneumonectomy, $\mathbf{1 . 2 \%}$ for lobectomy, and $\mathbf{0 . 8 \%}$ for a lesser operation, which showed a significant difference between pneumonectomy and lobectomy $(p<0.01)$. The mortality by age was $0.4 \%$ for patients younger than 60 years, $1.3 \%$ for those aged 60 to $69,2.0 \%$ for those aged 70 to 79 , and $2.2 \%$ for those aged 80 or older, which showed significant differences between the less than 60-year and 60- to 69-year-old groups, and between the 60- and 69-year-old and 70- and 79-year-old groups $(p<0.01$ and $p=0.047$, respectively). Pneumonia and respiratory failure caused most deaths (51.6\%). Conclusions: The operative mortality in Japan for thoracotomy in lung cancer was satisfactorily low. The results of this study on a large population could serve as a standard when discussing the operative outcome of lung cancer. (J Thorac Cardiovasc Surg 1998;115: 70-3)
Tom oday, lung cancer is one of the major causes of death. Evaluation of the operative outcome thereof is important to improve operative procedures and increase patients' quality of life by selecting an optimal therapy.

The 30-day operative mortality in 2220 lung cancer cases in North America was reported in $1983^{1}$ and, to date, has been referred to as the standard.

It has been more than 10 years, and the perioperative management has improved. From this, it may be natural to anticipate a more favorable operative outcome. Although several investigators

Editor of Journal of The Japanese Association for Chest Surgery ${ }^{\mathrm{a}}$; Member of The Japanese Association for Chest Surgery ${ }^{\text {b; }}$ Chief of The Academic Committee of The Japanese Association for Chest Surgeryc; Fourteenth President of The Japanese Association for Chest Surgery. ${ }^{d}$

Received for publication June 13, 1997; revisions requested Sept. 2, 1997; revisions received Sept. 22, 1997; accepted for publication Sept. 22, 1997.

Address for reprints: Hiromi Wada, MD, Department of Thoracic Surgery, Chest Disease Research Institute, Kyoto University, 53 Shogoin Kawahara-cho, Sakyo-ku, Kyoto, 606, Japan.

Copyright (c) 1998 by Mosby, Inc.

$0022-5223 / 98 \$ 5.00+0 \quad \mathbf{1 2 / 1 / 8 6 3 3 7}$ have reported their operative mortalities in a population of several hundred cases, 2,3 in the aged groups, ${ }^{2-7}$ or in cases with limited operative procedures, ${ }^{8,9}$ and various stages, ${ }^{10,11}$ no one has made a survey of the operative mortality of lung cancer in a large population comprised of several thousand cases, except for one. ${ }^{12}$

This article reports on the Japanese Association for Chest Surgery 30-day study of operative deaths after thoracotomy in more than 7000 lung cancer cases in a 1-year period. The overall profile of Japanese lung cancer surgery is described, and a standard for comparing operative results in worldwide series is provided.

\section{Patients and methods.}

The Japanese Association for Chest Surgery is the only medical association in which almost all Japanese institutions related to lung cancer surgery participate. In this study, the association distributed questionnaires to 312 member institutions and analyzed valid data returned from 200 institutions. The disease for analysis was lung cancer, regardless of whether it is primary or recurrent. The observation period was from January 1994 through December 1994. The data were collected and analyzed retrospectively.

The number of operations, number of deaths, and mortalities were analyzed according to the operative 
Table I. Thirty-day operative mortality with thoracotomy for lung cancer by operation

\begin{tabular}{|c|c|c|c|c|}
\hline Procedure & $\begin{array}{c}\text { No. of } \\
\text { operations }\end{array}$ & $\begin{array}{l}\text { No. of } \\
\text { deaths }\end{array}$ & $\begin{array}{c}\text { Mortality } \\
(\%)\end{array}$ & $p$ Values \\
\hline Pneumonectomy & 586 & 19 & $3.2\}$ & \multirow{4}{*}{$\begin{array}{l}p<0.01 \\
p=0.269\end{array}$} \\
\hline Lobectomy & 5609 & 67 & $1.2\}$ & \\
\hline $\begin{array}{l}\text { Less invasive } \\
\text { operation }\end{array}$ & 904 & 7 & $0.8\}$ & \\
\hline Total & 7099 & 93 & 1.3 & \\
\hline
\end{tabular}

procedure and age, and the causes of operative deaths were summarized. The operative procedures were divided into pneumonectomy, lobectomy, and less invasive operations (segmentectomy, partial resection, exploratory thoracotomy, and so on). Video-assisted thoracoscopic surgery was not included. Ages of the participants were divided into less than 60 years old, 60 to 69 years old, 70 to 79 years old, and 80 years and older. The operative mortality was defined as death within 30 days of operation.

Statistical analysis was performed by goodness test of fit for $\chi^{2}$ and $\chi^{2}$ test for independence with a Stat View-J4.02 (Abacus Concepts, Berkeley, Calif.). A $p$ value less than 0.05 was considered significant.

\section{Results}

The total number of thoracotomies for lung cancer performed at 200 member institutions during 1 year was 7099. Institutions performing fewer than 40 thoracotomies per year occupied more than $65 \%$ $(135 / 200)$. On the other hand, those performing 100 or more thoracotomies per year were less than 5\% $(8 / 200)$. The mean number of operations per institution was 35.5. Ninety-three deaths occurred within 30 days after operation in 7099 cases, with a 30-day operative mortality of $1.3 \%$.

Pneumonectomy was performed on 586 patients (8.3\%), lobectomy on $5609(79.0 \%)$, and less invasive operations on $904(12.7 \%)$. Nineteen patients died after pneumonectomy (3.2\%), 67 after lobectomy $(1.2 \%)$, and 7 after a less invasive operation $(0.8 \%)$. A significant difference in operative mortality was observed between pneumonectomy and lobectomy $(p<0.01)$ (Table I).

The number of operations by age and the proportion of all the operations was 1893 (26.7\%) for the group less than 60 years old, $2876(40.5 \%)$ for the group 60 to 69 years old, 2105 (29.7\%) for the group 70 to 79 years old, and 225 (3.2\%) for the group 80 years old or older. The number of deaths and 30-day operative mortality by age were $7(0.4 \%)$ for the group less than 60 years old, $38(1.3 \%)$ for the group 60 to 69 years old, $43(2.0 \%)$ for the group 70 to 79 years old, and $5(2.2 \%)$ for the group 80 years old or
Table II. Thirty-day operative mortality with thoracotomy for lung cancer by age

\begin{tabular}{|c|c|c|c|c|}
\hline Age (yr) & $\begin{array}{c}\text { No. of } \\
\text { operations }\end{array}$ & $\begin{array}{l}\text { No. of } \\
\text { deaths }\end{array}$ & $\begin{array}{c}\text { Mortality } \\
(\%)\end{array}$ & $p$ Values \\
\hline$<60$ & 1893 & 7 & $0.4\}$ & $p<0.01$ \\
\hline $60-69$ & 2876 & 38 & $1.3\}$ & $p=0.047$ \\
\hline 70-79 & 2105 & 43 & $2.0\}$ & $p=0.04$ \\
\hline$\geq 80$ & 225 & 5 & $2.2\}$ & $p=0.857$ \\
\hline Total & 7099 & 93 & 1.3 & \\
\hline
\end{tabular}

Table III. Causes of death within 30 days of operation

\begin{tabular}{lc}
\hline \multicolumn{1}{c}{ Causes of deaths } & No. of deaths \\
\hline Pneumonia/respiratory failure & 48 \\
Cardiac & 14 \\
Bronchopleural fistula/empyema & 5 \\
Pulmonary embolus & 1 \\
Postoperative hemorrhage & 9 \\
Others & 16 \\
\hline
\end{tabular}

older. The number of deaths in patients 70 years old or older was $48(2.1 \%)$. Significant differences were observed between the groups less than 60 and 60 to 69 years old and between the groups 60 to 69 and 70 to 79 years old ( $p<0.01$ and $p=0.047$, respectively) (Table II).

The causes of death within 30 days after operation are shown in Table III. Pneumonia and respiratory failure accounted for most deaths $(n=48,51.6 \%)$, followed by cardiac complications, postoperative hemorrhage, and bronchopleural fistula/empyema in that order.

\section{Discussion}

Lung cancer is one of the major causes of death in many developed countries, including Japan. Operation, chemotherapy, radiation, and immunotherapy have been used for this disease, but the overall therapeutic result is still unsatisfactory. At present operative intervention is indicated in patients in the early stages to achieve a complete cure. It is thus important to gather data on the perioperative mortality in lung cancer for improving outcome and selecting an optimal therapy.

The Lung Cancer Study Group (LCSG) published their detailed analysis on 30-day operative mortality for lung resections in a large population comprising 2220 lung cancer cases in North America in 1983. ${ }^{1}$ In this report the 30-day operative mortalities were $3.7 \%$ in the overall population, $6.2 \%$ for pneumonectomy, $2.9 \%$ for lobectomy, and $7.1 \%$ for the 
Table IV. No. of operations and mortality for pneumonectomy and lobectomy in recent literature

\begin{tabular}{|c|c|c|c|c|c|c|}
\hline \multirow[b]{2}{*}{ Reference No. } & \multirow[b]{2}{*}{ Year } & \multirow[b]{2}{*}{ Years analyzed } & \multicolumn{2}{|c|}{ Pneumonectomy } & \multicolumn{2}{|c|}{ Lobectomy } \\
\hline & & & No. & Mortality (\%) & No. & Mortality (\%) \\
\hline 1 & 1983 & $1979-1981$ & 569 & 6.2 & 1058 & 2.9 \\
\hline 2 & 1988 & $1970-1985$ & 287 & 6.9 & 352 & 4.0 \\
\hline 3 & 1991 & $1980-1987$ & 191 & $6.8^{*}$ & 280 & $3.9^{*}$ \\
\hline $12 \dagger$ & 1992 & 1983-1986 & 1529 & $10.1 \ddagger$ & 6569 & $3.4 \ddagger$ \\
\hline Present study & 1997 & 1994 & 586 & 3.2 & 5609 & 1.2 \\
\hline
\end{tabular}

*Defined as any death in the hospital after operation, regardless of length of time, or any death at home occurring within 30 days of operation. $\dagger$ Data from California hospital discharge abstracts.

$\ddagger$ Defined as inhospital deaths within 30 days after resection.

patients 70 years of age or older. The data have been referred to as a standard for analysis of operative mortality in lung cancer.

Since then, there have been some reports on operative mortalities in groups with a relatively small number of cases, ${ }^{2,3}$ aged patients, ${ }^{2-7}$ limited operative procedures, ${ }^{8,9}$ and selected clinical stage. ${ }^{10,11}$ However, no study has been done on the operative mortality in lung cancer in a large population comprising as many as several thousand cases, except for one. ${ }^{12}$ The operative mortality in this report, however, is based on discharge abstracts, not on the data directly collected from attending doctors. Furthermore, the observation periods are long in many of the previous reports. ${ }^{2,6,7}$

This report was composed of more than 7000 cases, and the observation period was 1 year. Although several reports have pointed out that the operative outcome at selected institutions, such as university hospitals, would not reflect the level of general medical practice, ${ }^{5,12}$ the institutions participating in our study ranged from national centers and university hospitals to institutions performing fewer cases. We report on one of the largest analyses made to date about the operative mortality in lung cancer and describe the present status of surgery in Japan.

Although the proportion of patients 70 years old or older, commonly with more complications, increased from $20.4 \%$ to $32.8 \%$, the mortality in the whole series decreased greatly from $3.7 \%$ to $1.3 \%$ in our study compared with the LCSG report in 1983.

Such improvement may have resulted from the decreased proportion of pneumonectomy (from $25.6 \%$ to $8.3 \%$ ), the increased proportion of lobectomy (from $67.9 \%$ to $79.0 \%$ ), and the reduction in mortalities for pneumonectomy (from $6.2 \%$ to $3.2 \%$ ), lobectomy (from $2.9 \%$ to $1.2 \%$ ), the group 70 to 79 years old (from $7.0 \%$ to $2.0 \%$ ), and the group 80 years old or older (from $8.1 \%$ to $2.2 \%$ ), although the data in the elderly in the LCSG report were for lung resection.

The mortalities were $6.8 \%$ to $10.1 \%$ for pneumonectomy ${ }^{2,3,12}$ and $3.4 \%$ to $4.0 \%$ for lobectomy ${ }^{2,3,12}$ in the literature; in our study the mortalities were $3.2 \%$ for the former and $1.2 \%$ for the latter (Table IV). Compared with the mortalities of $4.9 \%$ to $17.0 \%$ for the patients 70 years old or older ${ }^{2-5}$ and $3.0 \%$ to $15.0 \%$ for the patients 80 years old or older $^{6,7}$ in the literature (some data are for lung resection as indicated in Table V ), our mortalities were $2.1 \%$ and $2.2 \%$, respectively. Mortalities in our survey were obviously low.

The possible reasons for such a low perioperative mortality are increasing cases in the early stages, resulting from the wide use of computed tomography and other diagnostic modalities ${ }^{13}$; improvements in operative techniques, anesthesia, circulatory, and respiratory management; and control of postoperative infection. Downstaging by induction therapy also may have contributed to the reduced mortality.

The pneumonectomy rate in this study was as low as $8.3 \%$. The operative indications for lung cancer in Japan are as follows. Patients with non-small-cell lung cancer in clinical stage I to IIIA are generally operated on, some patients with non-small-cell lung cancer in clinical stage IIIB (T4) with preoperative tumor reduction by induction therapy are operated on. Some patients with small-cell lung cancer in clinical stage I are also operated on. The others are not treated surgically.

In Japan, operations for lung cancer in clinical stage I have increased and those for patients in clinical stage IIIA have decreased ${ }^{13}$ because of the nationwide mass screening system. Moreover, surgeons generally try bronchoplasty or pulmonary arterioplasty to avoid pneumonectomy and conserve 
Table V. No. of operations and mortalities for thoracotomy in the elderly in recent literature

\begin{tabular}{|c|c|c|c|c|c|c|}
\hline \multirow[b]{2}{*}{ Reference No. } & \multirow[b]{2}{*}{ Year } & \multirow[b]{2}{*}{ Years analyzed } & \multicolumn{2}{|c|}{ Age $\geq 70$} & \multicolumn{2}{|c|}{ Age $\geq 80$} \\
\hline & & & No. & Mortality (\%) & No. & Mortality (\%) \\
\hline $1^{*}$ & 1983 & 1979-1981 & 453 & 7.1 & 37 & 8.1 \\
\hline 4 & 1987 & 1977-1984 & 64 & 9.4 & - & - \\
\hline 2 & 1988 & $1970-1985$ & 71 & 11.2 & - & - \\
\hline $3^{*}$ & 1991 & $1980-1987$ & 81 & $4.9 \dagger$ & - & - \\
\hline $5 *+$ & 1991 & $1983-1985$ & 94 & $17.0 \S$ & - & - \\
\hline 6 & 1994 & 1981-1991 & - & - & 40 & $15.0 \|$ \\
\hline $7^{*}$ & 1994 & 1974-1991 & - & - & 33 & 3.0 \\
\hline Present study & 1997 & 1994 & 2330 & 2.1 & 225 & 2.2 \\
\hline
\end{tabular}

*Data for lung resection.

$\dagger$ Defined as any death in a hospital after operation, regardless of length of time, or any death at home occurring within 30 days after operation. \$Data from Medicare hospital claims records.

$\S$ Defined as deaths within 30 days of admission.

|Defined as death within 30 days of operation or anytime during hospitalization.

postoperative lung function. ${ }^{14}$ These are some of reasons for the low rate of pneumonectomy.

Compared with the data from the $\mathrm{LCSG},{ }^{1}$ the causes of deaths have shifted from bronchopleural fistula and empyema to pneumonia and respiratory failure. As described above, operations for patients in the early stages have increased in Japan. This has brought the reduction of pneumonectomies and may have lessened bronchopleural fistula. Furthermore, although we do not have exact proof, the improvement of operative procedures and instruments or the appearance of drug-resistant pathogens may also account for this.

In conclusion, the results of our study on operative mortality in lung cancer in a large population exceeding 7000 cases could be used as a standard for discussing therapeutic outcome in patients with lung cancer. Thirty-day operative mortalities in our series were satisfactorily low: $1.3 \%$ in the overall population, $3.2 \%$ for pneumonectomy, $1.2 \%$ for lobectomy, and $2.1 \%$ for the patients 70 years old or older.

We are grateful to all the members of the Japanese Association for Chest Surgery for their contribution in collecting valuable data.

\section{REFERENCES}

1. Ginsberg RJ, Hill LD, Eagan RT, et al. Modern thirty-day operative mortality for surgical resections in lung cancer. J Thorac Cardiovasc Surg 1983;86:654-8.

2. Deneffe G, Lacquet LM, Verbeken E, Vermaut G. Surgical treatment of bronchogenic carcinoma: a retrospective study of 720 thoracotomies. Ann Thorac Surg 1988;45:380-3.
3. Kadri MA, Dussek JE. Survival and prognosis following resection of primary non small cell bronchogenic carcinoma. Eur J Cardiothorac Surg 1991;5:132-6.

4. Sherman S, Guidot CE. The feasibility of thoracotomy for lung cancer in the elderly. JAMA 1987;258:927-30.

5. Whittle J, Steinberg EP, Andersen GF, Herbert R. Use of Medicare claims data to evaluate outcomes in elderly patients undergoing lung resection for lung cancer. Chest 1991;100:729-34.

6. Naunheim KS, Kesler KA, D'Orazio SA, Fiore AC, Judd DR. Lung cancer surgery in the octogenarian. Eur J Cardiothorac Surg 1994;8:453-6.

7. Osaki T, Shirakusa T, Kodate M, Nakanishi R, Mitsudomi T, Ueda H. Surgical treatment of lung cancer in the octogenarian. Ann Thorac Surg 1994;57:188-93.

8. Mehran RJ, Deslauriers J, Piraux M, Beaulieu M, Guimont C, Brisson J. Survival related to nodal status after sleeve resection for lung cancer. J Thorac Cardiovasc Surg 1994; 107:576-83.

9. Gregoire J, Deslauriers J, Guojin L, Rouleau J. Indications, risks, and results of completion pneumonectomy. J Thorac Cardiovasc Surg 1993;105:918-24.

10. Sabanathan S, Richardson J, Mearns AJ, Goulden C. Results of surgical treatment of stage III lung cancer. Eur J Cardiothorac Surg 1994;8:183-7.

11. Shah R, Sabanathan S, Richardson J, Mearns AJ, Goulden C. Results of surgical treatment of stage I and II lung cancer. J Cardiovasc Surg 1996;37:169-72.

12. Romano PS, Mark DH. Patient and hospital characteristics related to in-hospital mortality after lung cancer resection. Chest 1992;101:1332-7.

13. Wada H, Tanaka F, Yanagihara K, et al. Time trends and survival after operations for primary lung cancer from 1976 through 1990. J Thorac Cardiovasc Surg 1996;112:349-55.

14. Wada H, Okubo K, Hirata T, Hitomi S. Evaluation of cases with combined bronchoplasty and pulmonary arterioplasty for the treatment of lung cancer. Lung Cancer 1995;13:113-20. 